\title{
REHABITAR NUESTRA CASA: UN RETO ECO-ÉTICO ANTE LA EMERGENCIA AMBIENTAL PLANETARIA
}

“Una sociedad que decide organizarse sin una ética mínima, altruista y respetuosa de la naturaleza, está trazando el camino de su propia autodestrucción

(Leonardo Boff)

\author{
ANDREA SOTELO CARREÑO \\ Doctora en Lenguaje y Cultura (C) de la Universidad Pedagógica y Tecnológica de Colombia UPTC \\ Magíster en Lingüística de la Universidad Pedagógica y Tecnológica de Colombia UPTC \\ Magíster en Desarrollo Educativo y Social de la Universidad Pedagógica Nacional \\ Especialista en Educación, Cultura y Política de la Universidad Nacional Abierta y a Distancia UNAD \\ Comunicadora Social - Periodista de la Universidad Externado de Colombia \\ Investigadora del Grupo de Investigación Innovaciones Pedagógicas \\ andsot33@hotmail.com
}

CARLOS FRANCISCO COVALEDA POLO

Estudiante de noveno semestre de la Licenciatura en Filosofía, Pensamiento Político y Económico. Diplomado en Docencia Universitaria. Vicerrectoría de Universidad Abierta y a Distancia - Universidad Santo Tomás, CAU Tunja. Estudiante investigador del grupo de investigación 'Innovaciones Pedagógicas'. Estudiante Coordinador del Semillero de Investigación 'Aleteia'. francisconal21@hotmail.com

\section{Cómo citar este artículo:}

Sotelo, A \& Covaleda, C. Rehabilitar nuestra casa: Un reto eco-ético ante la emergencia ambiental planetaria. Espiral, Revista de Docencia e Investigación. 1, (1), 75 - 82

\begin{abstract}
Resumen
El presente artículo trata de la necesidad que existe en la actualidad de que la educación responda a la formación de un ser humano que entienda y sea consciente de la relación plena del hombre con aquellos avatares cósmicos y el infnito número de microorganismos que regulan el actuar y el proceso evolutivo de este macrocosmos; para que ello se dé, se propone que la educación instaure una perspectiva axiológica que le permita al hombre restituir su propia dignidad en la medida que recupere su relación íntima con la naturaleza, y en este sentido, su prioridad antropológica vaya desde las pinceladas de una relación armónica hombre-naturaleza hasta la perspectiva ecológica de las polifonías que han entendido que el objeto, frente a la acuciante realidad ambiental, establece un camino ético para volver a habitar nuestra Tierra.
\end{abstract}

Palabras Clave: educación, hombre, naturaleza, relación, ética

\begin{abstract}
This article is about an existing need nowadays to make education support the human being's integral formation who can understand and be aware of the full relationship between the man and those cosmic avatars and the endless micro-organisms that regulate the acting and the evolutionary process of these macrocosms; to lead this process, it is proposed that education restores a perspective of human values which lets the man recover his own dignity as well as his intimate relationship with nature, and in this sense, his anthropology priority can go from the brushstrokes of a harmonic relationship to the ecological perspective of the polyphonies which have understood that the object, opposite to the pressing environmental reality, is to establish an ethical way to re-inhabit our Earth.
\end{abstract}

Key words: education, man, nature, relation, ethic. 


\section{Introducción}

Cuando la mirada del hombre indaga por las fbras más íntimas de su realidad existencial, en este momento coyuntural de la historia, se refeja en sus pupilas la silueta de ese ser evocado por la supremacía de la inconsciencia, de una ausencia del sentido crítico y de la vida materialista, para dar como último resultado un ser deformado y desfgurado por su propio quehacer. Esta estampa es precisamente el grueso muro con el que el docente se golpea en su realidad y que aturde sus juicios infnitos con la caricaturesca fgura de seres que se dicen ser porque procuran la supervivencia y no el desarrollo pleno de su ser.

Esta realidad es la que empuja a dirigir hoy la mirada crítica a un ser enfermo que no se reconoce a sí mismo en su conjunto, en su ser holístico y que mueve al docente y al 'inconforme' a depurar esta cruda imagen con la posibilidad de abrir nuevos caminos de ascensión humana. El panorama descrito tiene que llevar al pensador y formador de esta realidad actual a escrutar en el fondo de lo que se contempla y poder establecer parámetros de formación que no multipliquen la realidad mísera de conformismo, de inconsciencia y de solvencia materialista. Pues los formadores hacen parte también del grueso que participa en la construcción de esta imagen desdibujada.

El hombre es un ser complejo y está en un estado de tensión hacia la perfección, es perfectible, visión que llegó gracias al ingenio de Santo Tomás de Aquino. Desde esta realidad, y en primera instancia, es menester cobijar al hombre desde una perspectiva de conjunto, donde todas sus dimensiones aboguen por su integralidad. Se habla de cinco dimensiones fundamentales en el hombre: espiritual, social, psicoafectiva, intelectual e interpersonal (Garzón, 2011). Asimismo, la dimensión social es la que por aquella relación del hombre con su entorno y, al mismo tiempo, se convierte en el pilar de una refexión actual a saber del hombre y la naturaleza.

En este momento coyuntural, urge una mirada escrutadora que logre vislumbrar la verdad ética y social que tiene el hombre con su entorno. Por esto, se ha querido plasmar una realidad percibida desde lo subjetivo hasta el papel colectivo con el cual se ejercita hoy este panorama relacional. No se puede hablar del hombre sin aludir a aquella dimensión que amerita especial interés en esta etapa histórica y existencial: la relación hombre-naturaleza.

La realidad misma nos encamina hacia esta perspectiva, basta mirar las noticias que nos envuelven, por ejemplo, el panorama japonés con los reactores nucleares de Fukushima, el tsunami (Cervera, 2011) y toda esta ola que algunos han denominado 'catastrófca' que no es más que el resultado de esta relación hombre-naturaleza. Hallazgos, descubrimientos, innovación, crecimiento técnico son premisas de la nueva generación que no mide las consecuencias de sus inventos o avances, ya que carece de una axiología ecológica que ponga por encima de la ciencia y de todo su acervo, el objetivo de procurar hacer al hombre cada vez más humano. Además, que el desarrollo científco se oriente a favor del mismo hombre y, por ende, de su entorno: naturaleza y medio ambiente. Por estas razones, urge una mirada crítica y refexiva que permee el actuar del formador y pensador de hoy, con el fn de que genere un compromiso formativo que lleve a los formandos y a todas aquellas personas que quieren desarrollarse integralmente a actuar a favor de una conciencia ecoética tendiente a superar la emergencia ambiental y poder establecer nuevas formas que permitan reivindicar el actuar del hombre para volver a habitar la Tierra, nuestra casa, en una nueva relación armónica hombre-naturaleza. 


\section{Una aproximación a la realidad}

Atenuar la realidad deshumanizante que afronta el ser humano en esta etapa histórica de desarrollo y cientifcismo, es continuar con el sin sentido y la falta de una conciencia crítica, motores de una permisividad y pasividad de tantas estancias de malformación y de gestación de conductas anti éticas en relación con el hombre y su entorno, especialmente, su medio natural. Asimismo, es casi imposible soslayar las crisis que envuelven todo el entramado posmoderno de la historia, acumulación, por llamarlo así, de crisis educacional, política, económica y ambiental. Por eso, unido a la Doctora Patricia Noguera (2011), quien cita al flósofo y poeta Ángel Amaya, se tiene en este momento una 'crisis civilizatoria' que exige vehementemente una acción inmediata por parte del hombre.

Ya algunos flósofos y pensadores denunciaban los avatares técnicos y tecnológicos, deshumanizadores que abogan por la dependencia globalizante y consumista, como los llamados por el Profesor Borda-Malo (2011) Profetas del Desierto:

"Las consecuencias que ocasionará la desacralización del cosmos y del ser humano (...) Los tiempos modernos gestan un monstruo de tres cabezas: el racionalismo, el materialismo y el individualismo. $\mathrm{Y}$ esa criatura que con orgullo hemos ayudado a engendrar, ha comenzado a devorarse a sí misma. ¡No se trata solamente de la crisis del Sistema Capitalista, sino de toda una concepción del mundo y de la vida humana basada en el endiosamiento de la técnica y la explotación del hombre por el hombre!"
Dentro de la educación también se ahonda y su hunde el dedo en la llaga de esta crisis. Las ciencias naturales han sido parte de un programa educativo, sin embargo, la realidad misma hace ver que no pasa de allí, de un estudio somero que responde a unos logros establecidos generados inclusive sin conciencia alguna. No hay realmente un esfuerzo por hacer de las asignaturas de las ciencias naturales una oportunidad de restablecer el equilibrio en la relación hombrenaturaleza.

Si nos situamos en el ámbito universitario, fácil es profesionalizar el conocimiento $\sin$ atender verdaderamente al ejercicio formador que genere procesos de ascensión humana para lograr una formación holística y así una realidad científca y ética que conlleve a un crecimiento bilateral entre el hombre y la ecología. El objetivo único de la perspectiva educativa de los colegios e instituciones es tratar de 'meter', palabra que, aunque coloquial, de profunda utilidad en este contexto son conocimientos anteriormente descubiertos sin ninguna articulación con la realidad circundante. En cambio, sí es de preocupación que el niño y el joven de hoy apelen por el conocimiento cientifcista y tecnológico que lo mantenga dentro de la maraña que ha construido el postulado globalizante que envuelve hoy a toda la sociedad.

Esto trae como consecuencia que el discente de hoy establezca una relación de depredación respecto del ambiente que le rodea. No hay una conciencia guía que genere procesos racionales de causas específcas de los actos y las consecuencias a presentarse por estos mismos. Simplemente, la sociedad se convierte en un 'hábitat', palabra estudiada en los grados del colegio 
pero nunca presentada en su sentido pleno, que tiene que estar supeditado al deseo caprichoso de consumo. Esta realidad afecta directamente todo el medio ambiente en el que el hombre pretende alcanzar su felicidad y realización.

Desde el seno de la educación no hay un compromiso veraz y acuciante que permita a los formadores articular su materia y todo el entramado conceptual, teórico e intelectual al ejercicio ético de los formandos, futuros hacedores de verdad, como lo expone el lema de la Universidad Santo Tomás, desde su fundación. En las manos de personas que aboguen por una conciencia sentada en los valores éticos que permita una relación plena con el entorno, está el dinamismo que se debe fomentar en los procesos educativos de formación, como lo afrma Luis Orozco (2008)“a ellos (los profesores) les corresponde la educatividad, es decir, la capacidad de ejercer infuencias positivas en el educando, contribuyendo de esta manera al desarrollo integral del ser humano"

\section{El reto eco-ético para volver a habitar nuestra casa}

Muchas veces se hace realmente difícil establecer una polifonía de aseveraciones de personas que ven con urgencia la formación ética para una relación vital entre hombre y naturaleza, que complemente $y$ haga efcaz el compromiso integral al cual pretende el hombre llegar en su ser -en-formación, para restablecer la armonía del compromiso por hacer del planeta nuestra propia casa. El reto educativo tiene como premisa la acucia de una ética garante de un mejor desarrollo y convivencia del hombre y su entorno, pues de nada sirve una reiteración de con- ceptos sin sentido si no tocan el fondo ético que movilise al formando al compromiso ecológico que debe tener hoy en pro de su desarrollo pleno en esta casa llamada Tierra.

Las políticas de liberalización y de globalización, tejen una maraña de consumismo que adormece la conciencia ecológica (Olarte, 2007), de la cual se puede deducir que la crisis ambiental manifestada en la coyuntura histórica actual obedece a la incapacidad del hombre para asumir su ser en relación con el entorno en el que se desarrolla. Por tanto, frente a la realidad de las políticas económicas que surgen en los países desarrollados, la formación que se ha de impartir debe velar por una formación axiológica que refuerce el principio supremo de la vida ya que ello cobija la esfera natural que propicia la vitalidad y la existencia.

La trama de la vida está realmente en contacto con todo cuanto se relaciona con el hombre y así debe entenderlo el objetivo educativo para apelar por una jerarquización axiológica que genere en el hombre de futuras generaciones el compromiso adquirido con el entorno que le sostiene y le brinda la posibilidad de generar vida. La educación actual ha de responder a la relación plena del hombre con aquellos avatares cósmicos, con los animales, las plantas y el infnito número de microorganismos que regulan el actuar y el proceso evolutivo de este macrocosmos.

En fn, hay una necesidad de que la educación encamine sus empresas al fortalecimiento eco-ético que genere una conciencia crítica en el proceso formativo para asumir su propia realidad de hombre y su recíproca relación con el medio en el que se desenvuelve. El proceso educativo aduce y responde por un ser holístico, de esta manera se podrá decir junto a Savater (1997): 
"La verdadera educación no sólo consiste en enseñar a pensar sino también en aprender a pensar sobre lo que se piensa y este momento refexivo, el que con mayor nitidez marca nuestro salto evolutivo respecto a otras especies, exige constatar nuestra pertenencia a una comunidad de criaturas pensantes".

El marco eco-ético abogará por un hombre comprometido con la totalidad de su ser y con la realidad completa para discernir cada momento evolutivo y resguardar los recursos naturales que hacen parte de su existencia misma. Asimismo, no habrá ya una conciencia manipulada por la sociedad sino un hombre crítico que asume consciente y refexivamente el legado ecológico y dirigirá con sapiencia el destino de los recursos para su pleno empleo a favor de su crecimiento humano integral, claro está, sin deterioro excesivo de las fuentes vitales ecológicas. Desde el marco eco-ético que podamos instaurar para ser aprehendido por nuestros discentes, podremos darle al formando y al hombre de hoy los argumentos y los asideros sufcientes que equilibren la relación con nuestro medio ambiente para hacer de nuestra casa, de ese 'oikos' griego, legado de occidente, un habitáculo propicio $\mathrm{y}$ enriquecedor que nos empuja a mirar los espacios abiertos para no hundirnos más en el fango de una crisis irremediable.

\section{Conclusión}

Desde esta realidad, sin lugar a dudas, el hombre debe ser formado para afrontar esta crisis ecológica, como lo afrma Pérez de Nucci (2011): "El problema del medio ambiente signifca un desafío de supervi- vencia para la humanidad que está pisando los umbrales del siglo XXI". La educación debe instaurar una perspectiva axiológica que le permita al hombre restituirse su propia dignidad en la medida en que recupere su relación íntima con la naturaleza. Por eso se debe afrmar que la eco-ética debe constituirse en una prioridad antropológica que vaya desde las pinceladas flosófcas de una 'physis' griega, hasta la perspectiva ecológica de las polifonías que han entendido que el hombre es un ser con la naturaleza y no en contra de la naturaleza, y que acucie por la necesidad de equilibrio que provoque una re-habitación de la casa, de la habitación, de la morada humana llamada Tierra.

La educación no debe abogar por el sueño prometeico (Borda-Malo, 2010 y Pérez de Nucci, 2011), con el cual se devora la esfera planetaria bajo los logos del neoliberalismo y del tecnifcismo, que ilustra uno de los siete pecados capitales de los que hablara Mahatma Gandhi: "ciencia sin conciencia". Por el contrario, todo proceso educativo debe generar un afrontamiento ético para la realidad tecnocrática que depreda el hogar que se le ha dado a la humanidad. Ya Edgar Morin da un primer paso con su libro 'Ciencia con conciencia' del Pensamiento Complejo, y todo el proceso refexivo y flosófco generado en esta instancia del acontecer humano ha de estar encaminado a deponer la desalmada conciencia cientifcista que pretende robarle a la humanidad el seno que le fecunda en desarrollo e integridad.

La naturaleza entera ha sido otorgada al hombre, es un regalo precioso, para que administre con razón y ética cada uno de los frutos que le da el universo, el cosmos. Asi- 
"El problema del signifca un desafío de supervivencia para la humanidad que está pisando los umbrales del siglo XXI". medio ambiente

mismo, el hombre ha de entender que tanto él como la naturaleza tienen un $f n$, un 'telos', que encausa el desarrollo y empleo de los factores naturales que favorecen su estadía en este hogar terrenal. Por tanto, hemos de

recuperar la genuina fnalidad de la relación hombre-naturaleza y transmitirla desde una atmósfera axiológica que promueva la urgencia del compromiso ecológico y establezca parámetros reales de educación integral en el pleno desarrollo de todas las dimensiones del hombre.

Pero: ¿Cómo hacerlo? Pregunta que, en la mayoría de los casos, castra el deseo de emprender el camino, de abrir los espacios propicios que lleven al hombre que se forma a optar por lo realmente humanizante y verdadero. Es necesario que, desde el ámbito educativo y bajo una atmósfera éticaambiental, nos llevemos a nosotros mismos y a nuestros estudiantes a buscar lo que nos pertenece. Por tal motivo, que esta atmósfera ética que se propone como asidero para rehabitar nuestra casa vaya desde la mirada crítica, ya enunciada, y recorra la senda de alternativas éticas que muevan y hagan éticos todos los actos humanos.

Esto se puede hacer si desde este momento nos decidimos a pasar a lo verdadero, como lo dice Sábato (2004), cuando cita a María Zambrano: "no se pasa de lo posible a lo real sino de lo imposible a lo verdadero". Y lo verdadero es transformar, haciendo de nuestra "no se pasa de de lo posible a lo real sino de lo imposible a lo verdadero" naturaleza un resurgir de cuidado y herencia, para que cuando nuestras generaciones futuras habiten esta Tierra puedan elevar la mirada de gracias a los actores éticos que les restituyeron su dignidad en la medida en que les otorgaron un mundo en el que es posible desarrollarse y alcanzar su realización plena.

Construyamos una ética del lenguaje, que reforme las estructuras y rompa los pseudo paradigmas de una sociedad neoliberal. Que al igual como propone el Doctor Luis Orozco (2008) "la formación exige que haya un ámbito donde sea posible crecer y, por eso, la mejor metodología para efectos de la formación integral tiene que ver con la contaminación" (p. 12);

Nosotros podamos contaminar el ambiente educativo con una ética capaz de reconducirnos y capaz de liberarnos del caos al restablecer el equilibrio de la relación hombre-naturaleza en una completa armonía. Transformemos los ambientes al reimaginar el mundo con ética y obtendremos un cambio mental que empezará a gestar acciones de humanización para recuperar lo que hasta este momento hemos perdido. Gritemos a una voz '¡Basta!', que lleve a todos los que nos escuchan a liberarse de ese antropocentrismo y vivan en la comunidad de vida. Una comunidad de vida que se cimenta sobre una ética del cuidado que nos lleve a ser cooperativos y solidarios para coexistir en nuestra casa común.

Es la hora del pensar ético que pone de manifesto la inconformidad de una antropovisión egocéntrica y manipuladora que tiene en esta instancia histórica una naturaleza como 'objeto' y no como 'medio', que es realmente su esencia en la relación íntima y recíproca que guarda con el hombre. Sólo desde la perspectiva eco-ética podrá dársele al hombre las herramientas sufcientes en el proceso educativo para salvaguardar el 
emporio ecológico desde una relación pluridimensional para el pleno empleo de los recursos naturales. Asimismo, el compromiso eco-ético generará una generación de nuevos seres ecóflos, que promuevan una conciencia justa y verdadera con la cual se pueda asumir el entramado ecológico actual y acabe por hundir aquellos vetos a toda manipulación del hombre sobre el cosmos.

Emerge entonces la necesidad de generar una atmósfera educativa que promueva la columna axiológica en torno a lo ecológico y genere en estudiantes, niños, jóvenes, adultos, una ciencia con conciencia, una ciencia con un 'ethos' que regula el crecimiento científco a favor del mismo hombre, en su desarrollo pleno, y de la naturaleza, en su proceso de conservación. Es la hora que desde esta formación de conciencia, desde esta atmósfera de eco-ética resurja la necesidad de que el hombre reconquiste la tierra y todos sus recursos, y reivindique su relación íntima para que pueda volver a habitar su casa.

Así queda planteado que el proceso educativo ha de partir hoy desde la pregunta ética: ¿Cómo debemos vivir? Para conciliar así el deseo impetuoso de cientifcismo y tecnología que depreda las reservas naturales y llegar en defnitiva a una instancia ética que sosiegue esta crisis ecológica para sacar del fango al hombre embotado en egocentrismo e inconsciencia. La perspectiva educativa desde el marco eco-ético complementará el objetivo formativo para restablecer la relación armónica del hombre con la naturaleza y favorecer así un ambiente óptimo que mejore los factores de producción y científcos. Toma de conciencia, educación sufciente y ética, y el compromiso encarnado y entraña- do por una ecología equilibrada han de ser refejo y resultado de la atmósfera eco-ética, de la axiología antropológica y de su convergencia en seres ecóflos que armonizan su existir con la naturaleza y el cosmos (Pérez de Nucci, 2011). Por esta mediación quedará fjo y cumplido el objetivo educativo que se centra en señalar el sentido de la educación como tarea esencialmente humanizadora y humanística (Villalobos, 2002), y el hombre podrá volver a habitar su casa.

Que hoy todos los formadores salgan a los espacios que tienen abiertos para adquirir el compromiso ético de arriesgarse por el Otro, de tal manera que se construya una nueva historia y todos esperemos, como lo dice Sábato (2004), a que una nueva ola de la historia nos levante con la fuerza del amor y el deseo de verdad, para terminar con el compromiso de rehabitar nuestra casa desde este nuevo paradigma ético que exige toda nuestra entrega, porque "sólo lo que se hace apasionadamente merece nuestro afán, lo demás no vale la pena" (Sábato, 2004, p. 187).

\section{Referencias bibliográfcas}

Ballesteros, E. (2010). Necesidad de la Bioética en la Educación. Revista OptantesBogotáD.C.: Promotoría Provincial de Comunicaciones.

Beltrán, H., Duarte, C., Henao, L., Londoño, P., Martá, J., Pongutá, F., y Vallejo, R(2007). Portafolio del aprendizaje. Campo Pedagógico: Formación y Educación. Bogotá, D.C.: USTA.

Borda-Malo, S. (2010). Juventud Tomista y Diálogo Academia - Fe: El desafío ecológico. Quaestiones Disputatae. Tunja: USTA.

Borda-Malo, S. (2011). Ernesto Sábato: homenaje a una obra prof-ética y eco-sófca en sus 100 años 
de vida (1911/2011). Trabajo presentado en el XIV Congreso Internacional de Filosofía Latinoamericana, Junio - Julio, Bogotá D.C.

Cervera, J. (2011, 15 de marzo). Fukushima: ¿Qué pasaría en el peor de los casos? Rtve.es. Recuperado el 3 de abril de 2011, de http:/ / www.rtve. es/ noticias/20110315/fukushima-pasaria-peor-casos/417028.shtml

Garzón, J. (2011). Dimensiones de la Persona. Recuperado el 3 de abril de 2011, de http:/ / www.slideshare.net/lafresita0911/dimensiones-del-ser-humano-1220949

Maya, A. (2001). La Razón de la Vida, 9 tomos sobre Ética Ambiental. Manizales - Medellín: IDEA Universidad Nacional.

Morin, E (2008) Introducción al pensamiento complejo. Barcelona Gedisa.

Noguera, P. (2011). Ethos Ambiental: Despliegues de una Estética del Habitar. Trabajo presentado en el XIV Congreso Internacional de Filosofía Latinoamericana, Junio - Julio, Bogotá D.C.

Nussbaum, M. (2005). El Cultivo de la Humanidad. Una Defensa Clásica de la Reforma en la Educación Liberal. Barcelona: Paidós.

Olarte, V. (2007). La Educación Superior en Colombia y sus Perspectivas en la Globalización. Quaestiones Disputatae. Tunja: USTA.

Orozco, L. (2008). Responsabilidad del Docente en la Formación Integral. Bogotá, D.C.: USTA.

Pérez de Nucci, A. (2011). Ética y Medio Ambiente: El desafío de fnes del siglo XX. Recuperado el 3 de abril de 2011, de http:/ / www.sem.intramed. net. ar/revista/009.htm

Savater, F. (1998). El valor de Educar. Barcelona: Ariel.

Sábato, E. (2004). Antes del fn. Barcelona: Seix Barral.

Universidad Santo Tomás. (2010). Modelo Educativo Pedagógico. Bogotá, D.C.: Autor.

Villalobos, E. (2002). Didáctica Integrativa y el Proceso de Aprendizaje. México D.F.: Editorial Trillas, S.A. 
